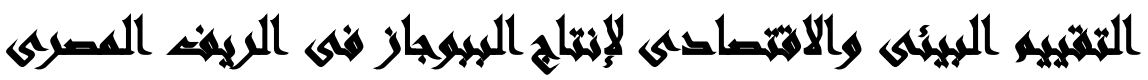

[V]

محمد سليمان محمود(')- هشام إبراهيم القصاص(ץ) - طه عبد العظيم محمد عبدالرازق(ץ)

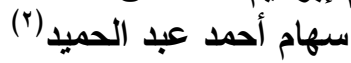

( ) جهاز شئون البيئة، وزارة البيئة ب) معهد الدراسات والبحوث البيائية، جامعة عين شمس البئ

\section{المستخليم}

تتمثل مشكلة البحث فى أن مصر تواجه مشكلة تراكم القمامة والمخلفات الحيوانية،

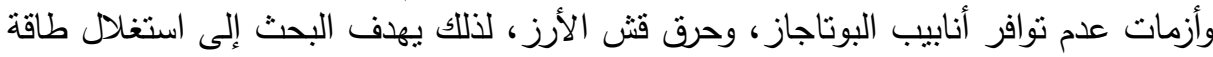

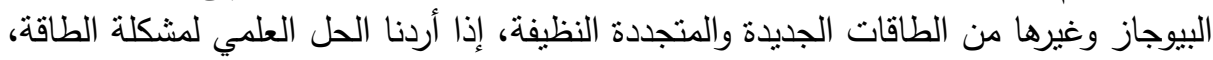

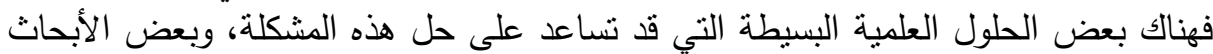

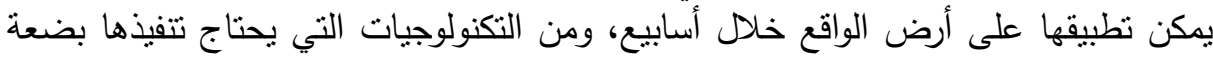

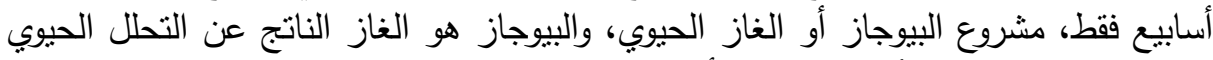

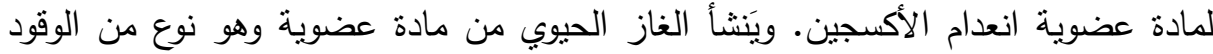
الحيوي، واستهدفت الدراسة إجراء النقييم الاقتصادى لطرق استغلانل المزارعين للمخلفات

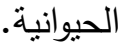

ويضمن مشروع البيوجاز طريقة آمنة للتخلص من بعض الرضاء المخلفات الحيوانية، وينتج

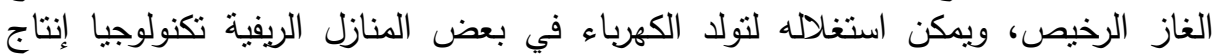

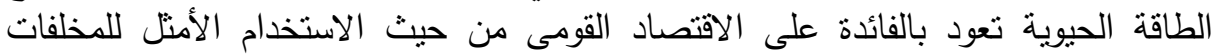

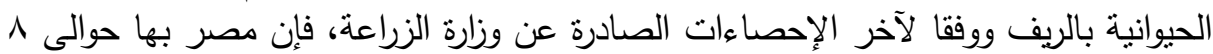

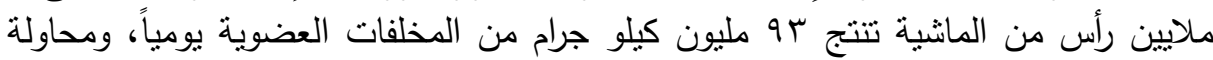

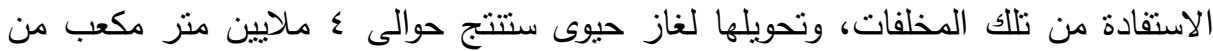

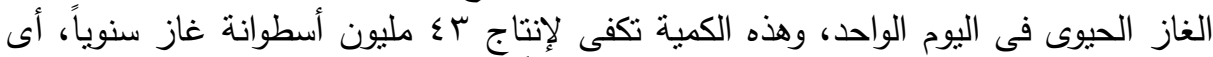

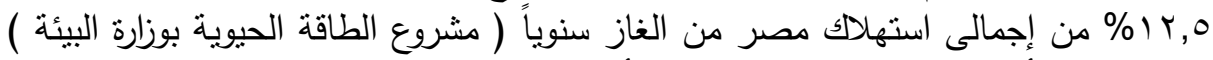

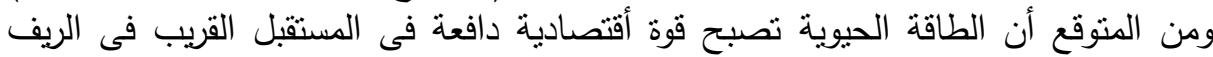

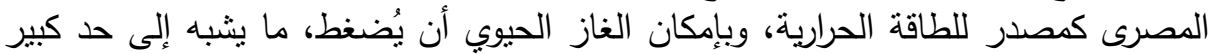

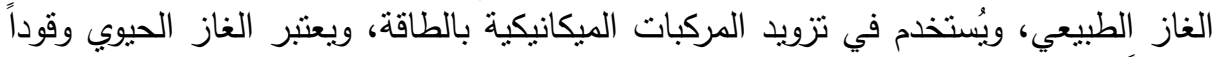

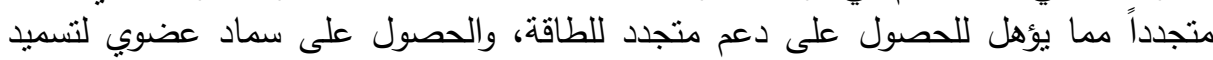

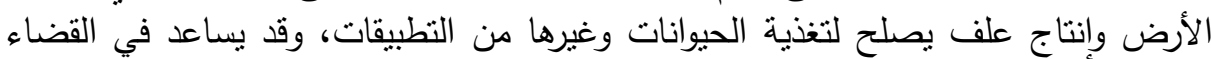
على تراكم المخلفات الحيوانية والنباتية. 
إن ازمة الطاقة وزيادة أسعارها فى مصر تطلبت دراسة وتتاول الاساليب الجديدة البديلة للحصول على الطاقة النظيفة لذا استهدف البحث التخان التخلص من الدخلفات الحيوانية بطريقة

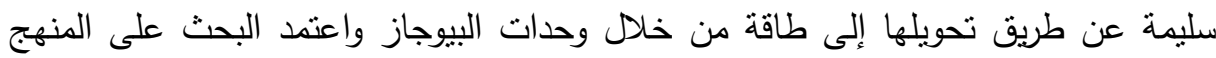

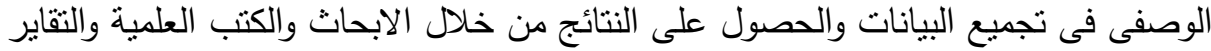
الدورية والمقالات و بينت نتائج البحث إلى أن استخدام وحدات البيوجات البان يحقق كفائة القتصادية

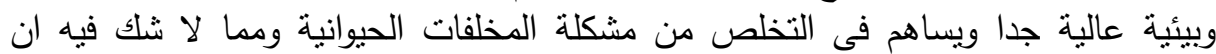

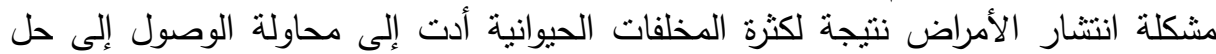

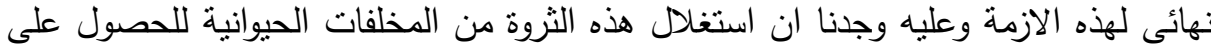

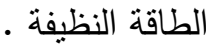
تم إجراء الدراسة الميدانية لعينة من المحافظات لعدد ال وحدة، ثم توزيعها على النحو

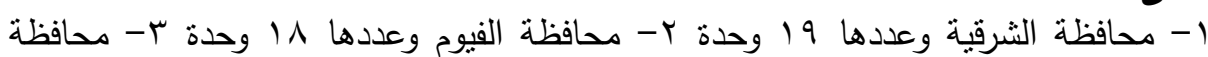

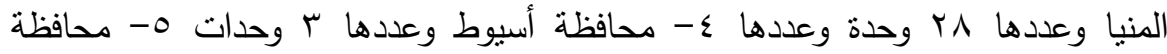

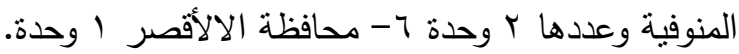

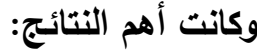

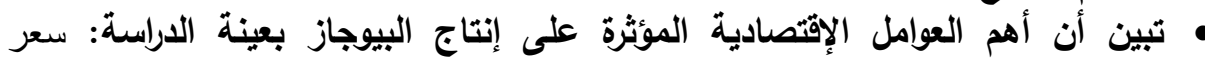

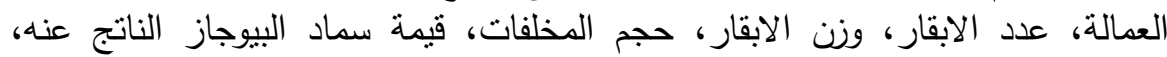

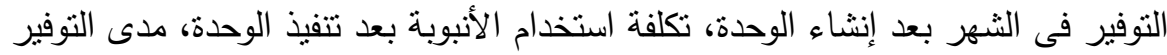

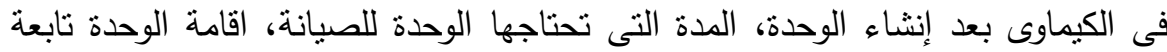

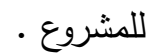

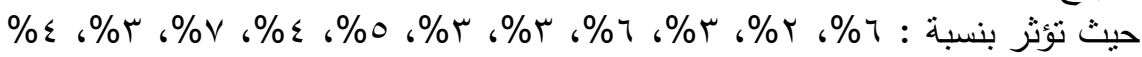

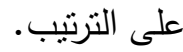
كما تبين أهم العوامل المرتبطة بالبعد البيئى والصحى بعينة الدراسة : قيمة سماد البيوجاز،

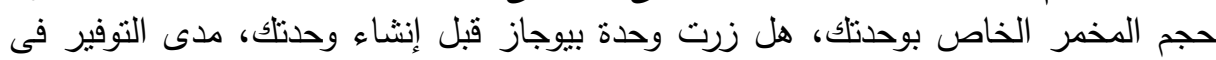

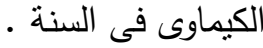

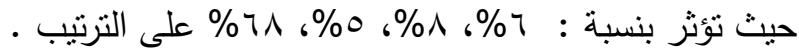

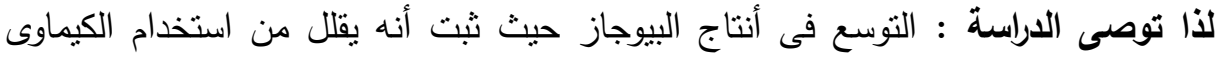

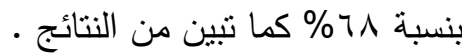

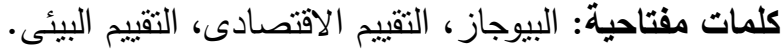

\section{ranarll}


أصبحت قضية البيئة وحمايتها والمحافظة عليها من مختلف أنواع الملوثات، واحدة من

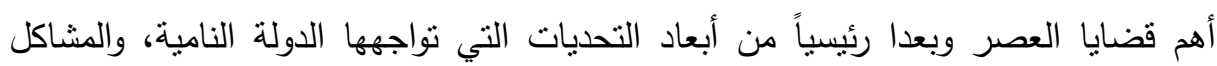

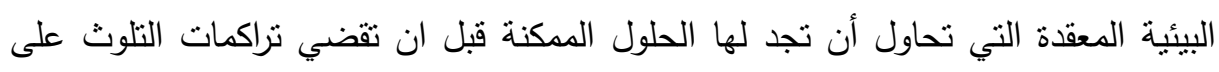

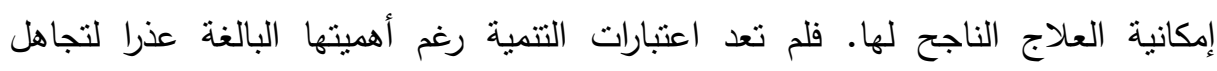

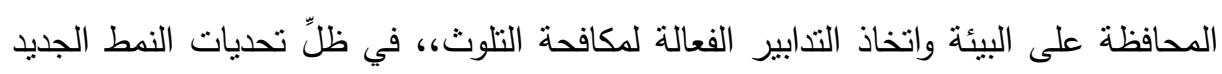
لعولمة العمليات الاقتصادية، تقاس بنظام طاقاتها المتجددة بأساليب بيئية تقنية حديثة. (سمير لئي

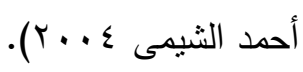

إن استبدال المصادر الطاقة المتجددة بالمصادر الطاقة الثقليدية هو مشروع إيكولوجي

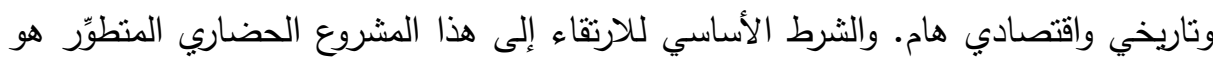
إنقان أساليب بيئية تكنولوجية غير معقدة بغية الوصول إلى قاعدة للمصادر الطاقة البديلة.

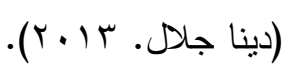
إن إمكانية نوليد التيار الكهربائي والطاقة الحرارية ومواد الاحتراق (وذلك لاستخدامها

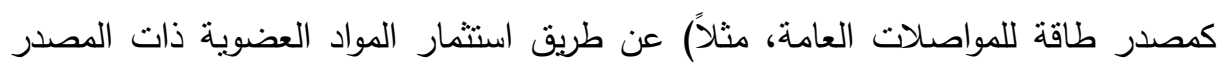

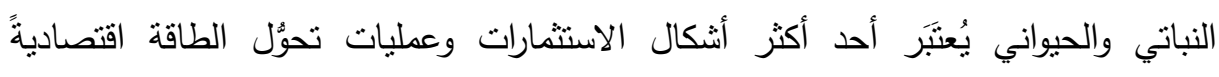

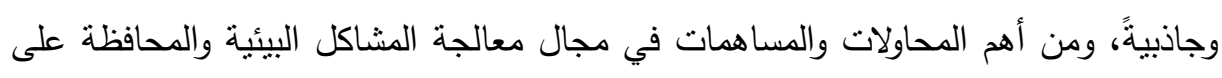

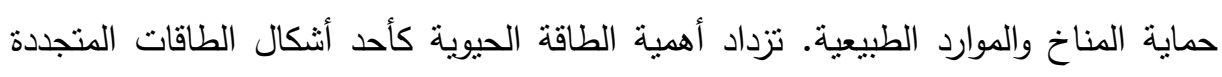

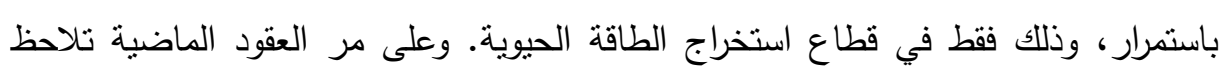

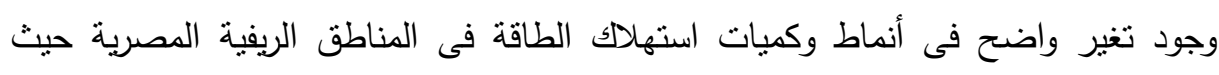

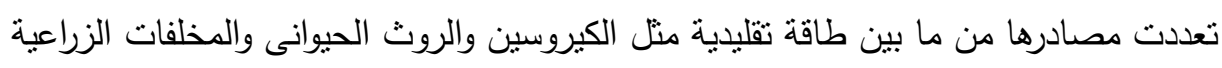

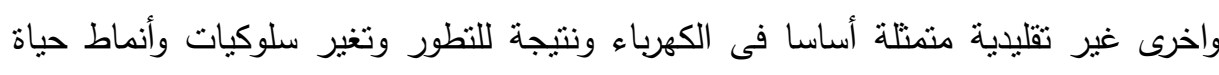

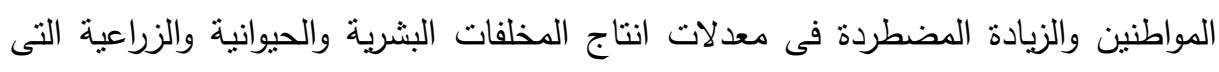
تعتبر كنز للقرية المصرية اتجهت الدولة إلى نتجيع الإستفادة من هذه المخلفات فى إيجاد مصدر بديل للطاقة، وهو إنتاج الغاز الحيوى باستخدام روث الحيوانات والمخلفات النباتية

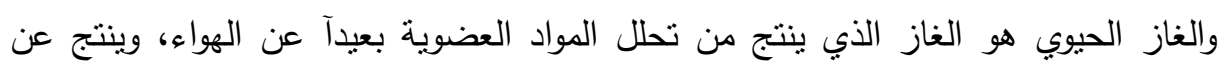

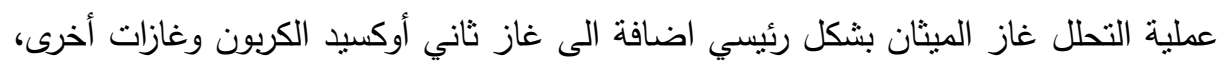

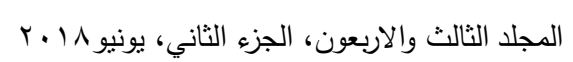


ويتكون الغاز الحيوي من تحلل المواد العضوية في بيئة لاهوائية وينتج عن هذه العملية الغازات التالية:

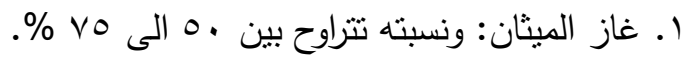

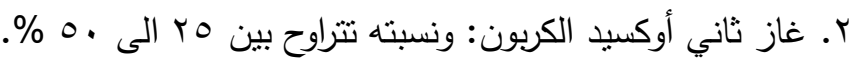

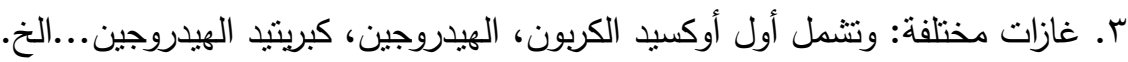

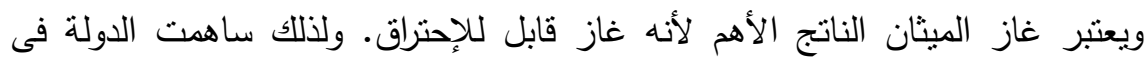
البحث عن مصادر بديلة للطاقة تحقق المردود البيئى والاقتصادى فى آن واحد، واتخاذ التدابير التى من شانها أن نرفع حصة الطاقة المتجددة المستدامة فى مزيج الطاقة، وتعظيم

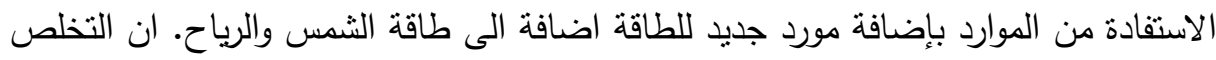
الامن من المخلفات الحيوانية والزراعية باستخدام منشأت الغاز الحيوى يساهم مساهمة كبيرة مئه

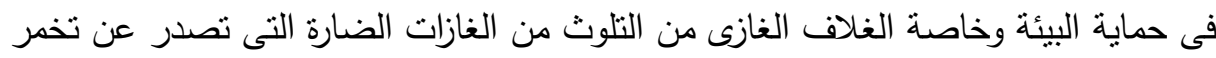

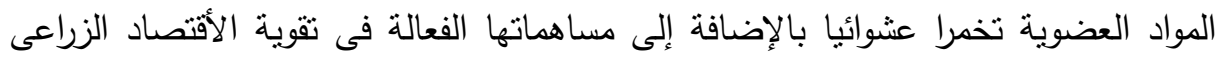

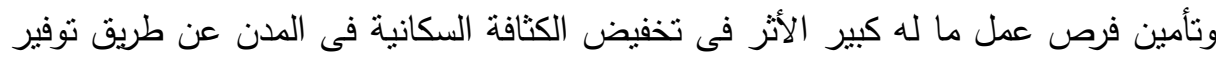

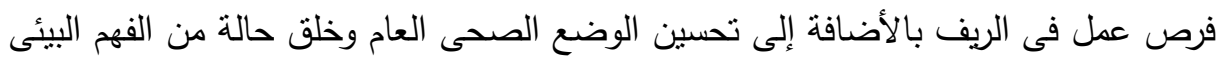

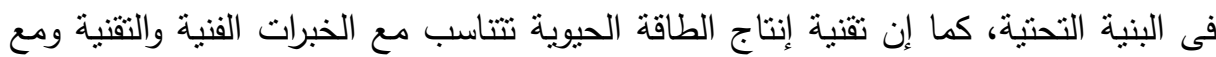
الموارد المحلية المتوفرة فى الريف المصرى والتى يمكن إستخدامها بتكاليف منخفضة وليه وسائل

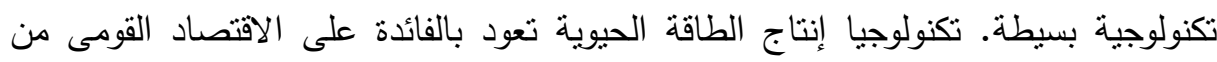

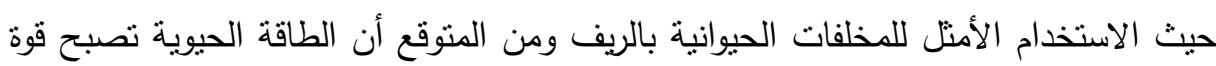
أقتصادية دافعة فى المستقبل القريب فى الريف المصرى. وكانت أهم النتائج: • تبين أن أهم العوامل الإقتصادية المؤثرة على إنتاج البيوجاز بعينة الدراسة: سعر

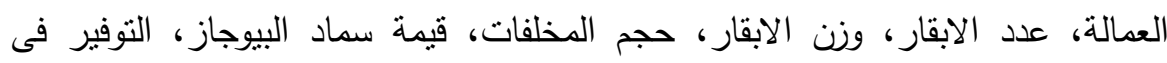

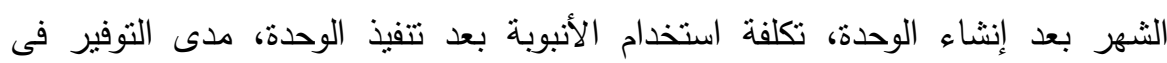


الكيماوى بعد إنشاء الوحدة، المدة التى تحتاجها الوحدة للصبانة، اقامة الوحدة تابعة للمشروع.

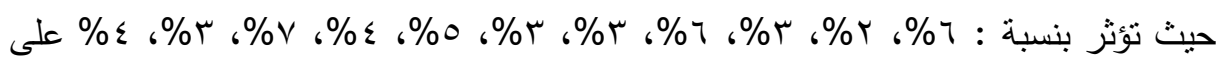
الترتيب.

• كما تبين أهم العوامل المرتبطة بالبعد البيئى والصحى بعينة الدراسة: قيمة سماد

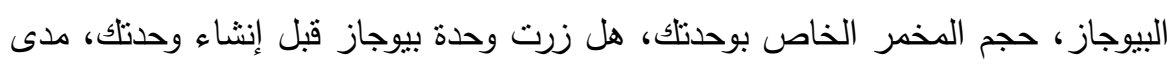
التوفير فى الكيماوى فى السنة.

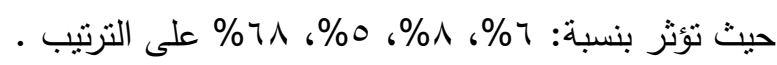
لذا توصى الدراسة: التوسع فى إنتاج البيوجاز حيث ثبت أنه يقلل من استخدام الكيماوى بنسبة

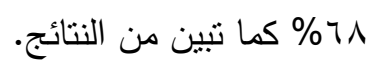

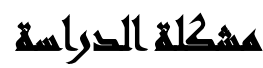

تتمنل مشكلة البحث فى زيادة كميات المخلفات الحيوانية والنباتية والتعامل الخاطئ معها

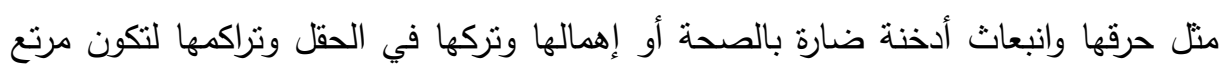
للحشرات والقوارض واحتمال مما يؤدي إلي تلوث البيئة.

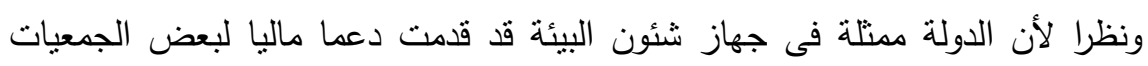
غير الحكومية والأفراد لتمويل إنثاء مخمرات إنتاج الغاز الحيوى إلى أن هذه التجارب لم لم يتم تقيمها بيئيا أو أقتصاديا.

\section{هدمثت الدراهة}

يهدف البحث إلى أجراء التقييم البيئي والاقتصادى لمشروعات الطاقة الحيوية ومدى

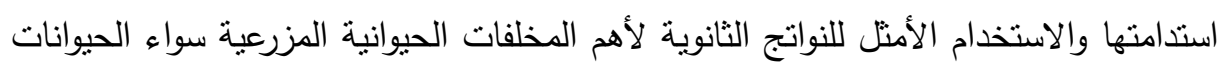
الكبيرة أو الصغيرة.

عن طريق الاستغلال الأمتل للمخلفات الحيوانية وإعادة استخدامها، مما يقلل من الآثار

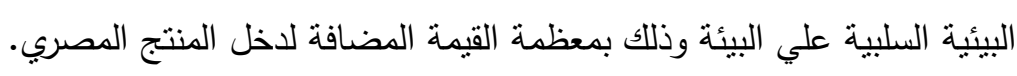




\section{الأسلوهب اللهثيه وهماتر البهياناهي}

اعتمدت الدراسة على البيانات الثانوية المنشورة بالإضافة إلى بيانات أولية من خلال

استمارة الاستيان استعان البحث بالبيانات الميدانية لعينة الدراسة التى نم إختيارها عمديا فى

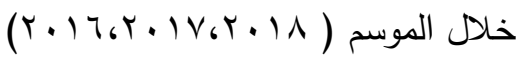
ايضا اعتمدت الدراسة على المنهج الوصفى والذى يقوم على محاولة ضبط كل العوامل الاساسية المؤثرة فى المتغير التابع مع التحكم فى المتغير المستقل بقصد تحديد ولثيد وقياس تأثيره على المتغير التابع وقد نم الاعتماد على البيانات الإحصائية من البيانات المنشورة والغير منشورة من الجهات الحكومية والغير حكومية (الأهلية) بالإضافة إلى بعض البحوث والدراسات

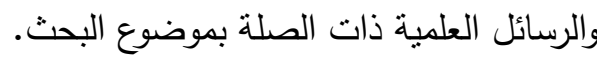

\section{أهمية القوراسم}

أهمية البحث تتمثل فى استغلال شئ غير مرغوب فيه وضار بالبيئة فى نوليد طاقة عن

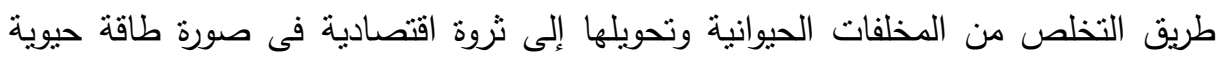
يستفاد به، ومن ثم فإن نتائج هذه الدراسة يمكن أن تضيف إلى الأطار النظرى للإراسات

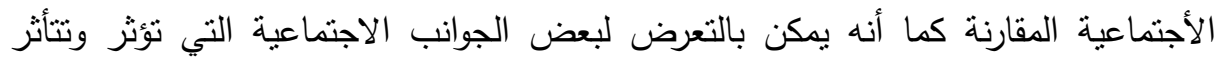

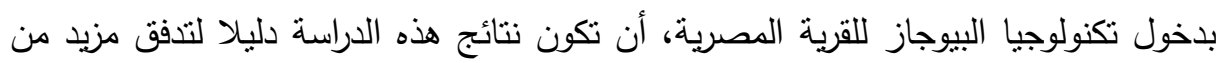
التكنولوجيات التي يعتقد أنها تتتاسب مع ظروف المجتمع المصري.

\section{هنوره التوراسة}

• توجد علاقة ذات دلاله احصائية بين إدارة المخلفات والصحة العامة للأفراد فى المجتمع. • توجد علاقة ذات دلاله احصائية بين حجم المخلفات وكمية الطاقة الناتجة. • توجد علاقة ذات دلاله احصائية بين تدوير المخلفات وزيادة الناتج القومى فى حالة دله التوسع فى استخدامه على مستوى المحافظات. 


\section{محستايت السراسمة}

نظرا لظروف البحث من حيث عدم حداثة ودقة البيانات المتاحة عن وحدات البيوجاز

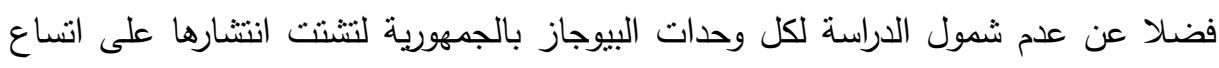
الريف المصري، فإن النتائج التي تم التوصل إليها لا بمكن تعميمها إلا على مستوى بلى

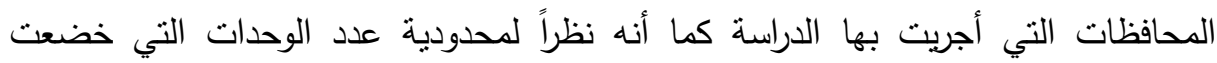
للاراسة لنطبيق معايير محددة في اختيار تلك الوحدات، فقد نم استخدام أسلوب المسح الثامل لكل مفردات المجتمع الاحصائي للاراسة في كل محافظة من المحافظات التي شملها البحث. وقد اهتمت الدراسة بتتاول أكبر المحافظات شمولا لوحدات البيوجاز في الوجه القبلي وكذلك من فئك في الوجه البحري.

ما معنى البيوجاز: يطلق كلمة البيوجاز Biogas أو الغاز الحيوى على مجموعة من الغازات الناجمة من تحلل المواد العضوية الرطبة بفعل بكتريا لاهوائية بمعزل عن الهواء

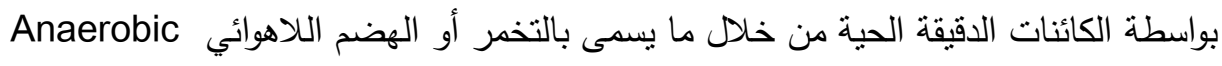

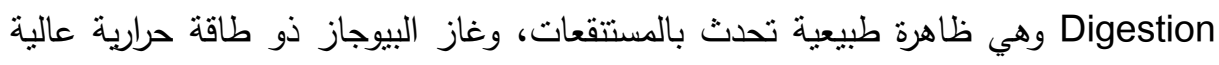
وهو يستخدم كمصدر لتلك الطاقة مباشرة أو بتحويله إلى صور الطاقة الأخرى الكهربائية

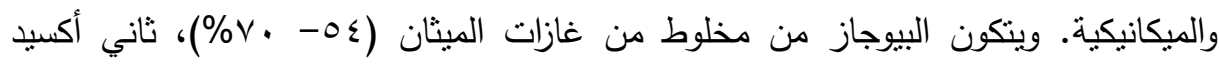

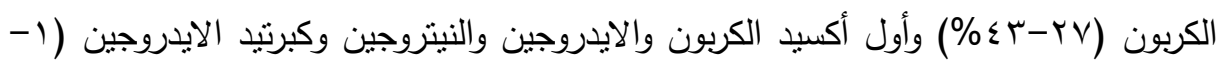

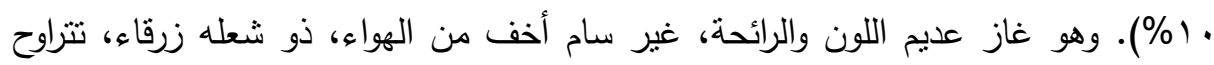

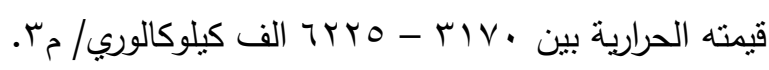

المخلفات المستخدمة في إنتاج (البيوجاز): تختلف المخلفات العضوية المستخدمة في إنتاج البيوجاز ، والمنتجة له تبعًا لنوعها ومصادرها ونظام معالجتها وفتزة تخميرها ودرجة الحرارة...، وتتنمل تلك المخلفات المستخدمة على الأنواع التالية: 1-المخلفات الحيوانية: روث الماشية؛ سماد الدواجن؛ سبلة الخيول؛ روث الأواعة الأغنام والماعز والجمال؛ مُخلفات الطيور المنزلية؛.... وغيرها. ب-المخلفات النباتبة: الأحطاب مثل (حطب الذرة، وحطب القطن)؛ وقش الأرز؛ والعروش الخضراء؛ ومُخلفات الصوب؛ والثمار التالفة..... وغيرها. 
ب-المخلفات الآدمبة: الصرف الصحي؛ وخزانات التحليل..... وغيرها.

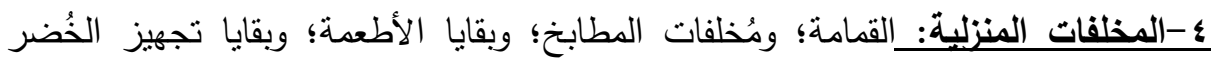
والفاكهة... وغيرها.

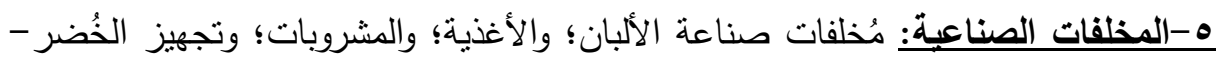
الفاكهة؛ ومُخلفات المجازر بأنواعها. צ-الحشائش: حشائش برية؛ ومائية؛ وورد النيل.... وغيرها. ( أحمد، السعيد محمد شعبان $(r \cdot)$ أما المخرجات أو النواتج فتتقسم إلى ثلاث أقسام: أولاً: الغاز الحيوي يتم جمعه وقياس ضغطه ومعالجته من آثار كبريتيد الهيدروجين ثم توزيعه واستخدامه. ثانتًا: نواتج مهضومة وتتمنل في سماد عضوي يتم تخزينه ونقله واستخدامه ومياه يمكن إعادة

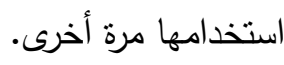
ثالثا: خفض التلوث وتحسين ظروف الحياة. فوائد انتاج البيوجاز : من أهمها:(IPCC2001) • إنتاج الطاقة النظفة: يساعد استخدام البيوجاز في توفير مصادر جديدة ونظيفة تساهم في ترشيد استهلاك الطاقة التقليدية (من الكهرباء والمواد البترولية)، حيث إن غاز البيوجاز غير سام ونظيف وليس لله عادم احتراق، ويستخدم مباشرة في الطهي والإنارة والتذفئة وتتثغيل ماكينات الري وتوليد الكهرباء، ويحتوي المتر المكعب من البيوجاز على طاقة وله تعادل المنتجة من ع, . كيلو جرام خشبًا، و > كيلو جرامات مخلفات نباتية أو حيوانية. • إنتاج سماد البيوجاز: حيث ينجم سماد عضوي عالي القيمة الغذائية للتربة الزراعية سواء في صورة سائل معلق (حيث يتم فصل الجزء الصلب عن السائل إما بالترسيب أو بإمراره على مهز زلطي وتجميع الراشح وخلطه بمياه الري لاحتوائه على بعض العناصر السمادية الذائبة)، أو فى صورة مجفف (حيث يكشط الجزء الصلب ويجفف في مكان مظلل ويعبأ 
في أكياس)، وينم لإضافته نثرًا قبل الزراعة أو يدفن في جور حول الأثجار المثرة أو الخثبية.

والسماد الناتج يتميز بارتقاع قيمته السمادية ومحتواه العالي من المادة العضوية والعناصر السمادية الكبرى والصغرى اللازمة لنمو النباتات، حيث نبلغ نسبة المادة العضوية

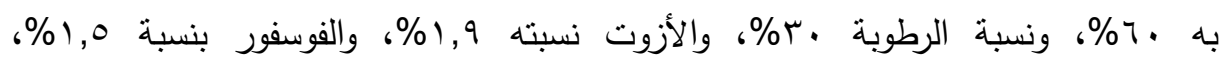
والبوتاسيوم 7, • \% ب، بالإضافة إلى عناصر سمادية صغرى بكميات ملائمة لنمو النباتات.

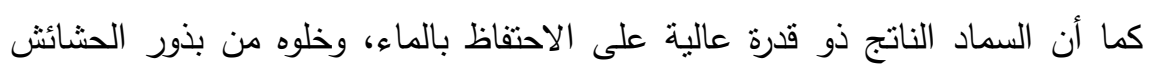
والميكروبات المرضية والطفيليات وغيرها من ناقلات الأمراض، بالإضافة إلى أنه عديم الرائحة وآمن صحيًا وطارد للحشرات المنزلية (منل الذباب والبعوض والفئران) لخلوه من الرائحة الجاذبة لها.

كما يعتبر السماد مخصب عضوي متكامل يقلل من استخدام الأسمدة المعدنية، ولقد أدى

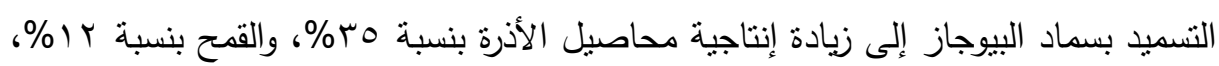

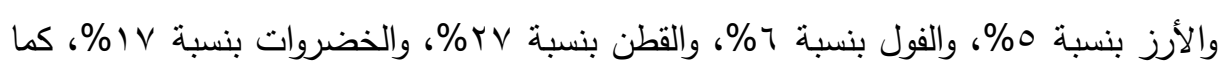

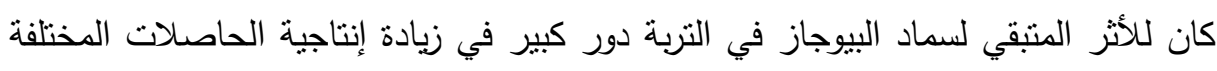

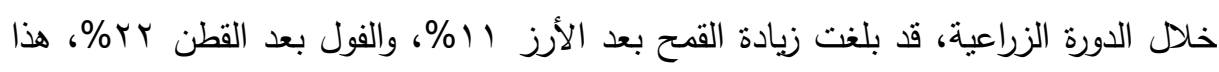

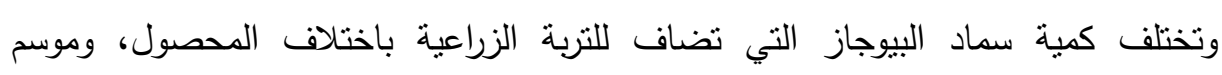

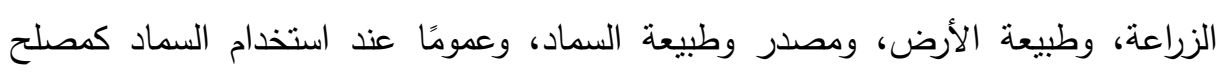

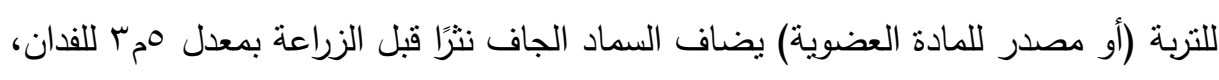

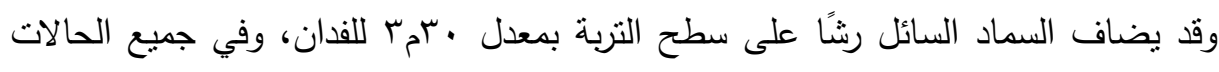
يجب أن يخلط السماد بالتربة بعد الإضافة. وعند استخدام سماد البيوجاز كمصدر للتساد للتسميد الأزوتي فإن السماد الجاف يضاف على أساس محتواه من النيتروجين وهو يعادل 10 كيلو جرامًا من النيتروجين في المنر المكعب من السماد الجاف، في حين أن السماد السائل يكون

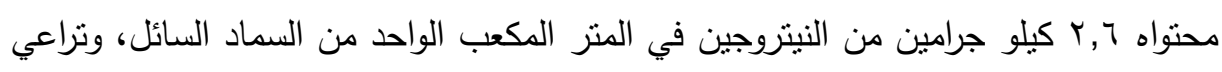

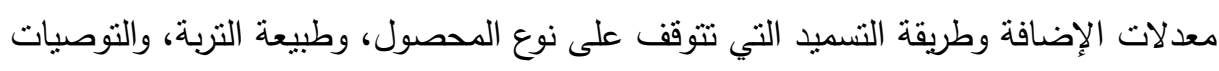

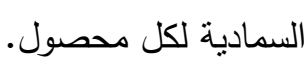


1. يساهم في القضاء على الحشائش: حيث يتم هضم بذورها داخل المخمر وبالتالي لا تكون هناك فرصة لإعادتها مرة أخرى للأراضي الزراعية.

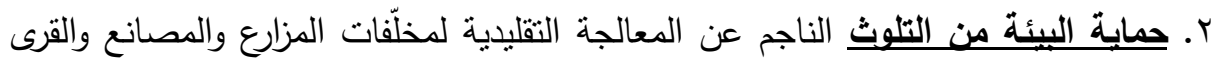
والمدن نتيجة الحرق. r. تقليل الاعتماد على الأسمدة الكيماوية: وذلك لتلافي أضرارها على صحة الإنسان والبيئة،

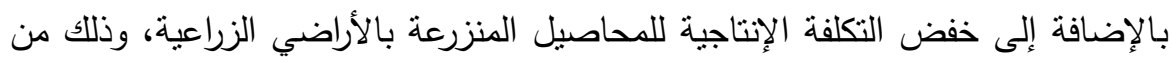
طريق إنتاج واستخدام سماد عضوي جيد يزيد من خصوبة التربة الزراعية.

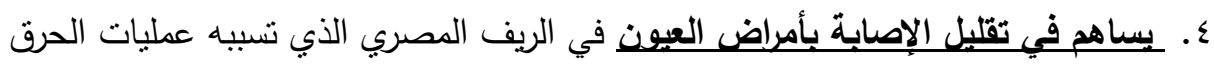
في الأفران الريفية وكذلك الحرق الناتج من استخدام الكوانين التي مازالت تستخدم في بعض الكفور المصرية. ه. تقليل الوقت الذي تستخدمه المرأة الريفية في إعداد الطعام واستغلاله في أهداف إنتاجية أخرى.

T. يساهم في حماية اليئة: من التلوث والمحافظة على صحة الإنسان والحيوان حيث يتم التخلص من الميكروبات والطفيليات الضارة التي تصيب الإنسان والحيوان والنبات. ( لارا فخرى ع (r. (r)

الهذف من إنثاء وحدة البيوجاز : في حالة زيادة الطلب على الغاز يُمكن زيادة فترة البقاء إلا

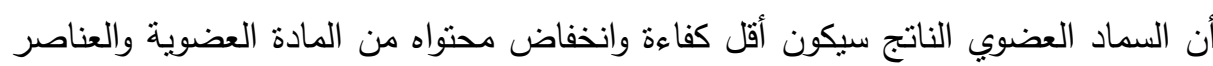

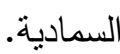

ولتوضيح ذلك فإن حساب وحدة البيوجاز لمزرعة مزودة بحظيرة تحتوي على 10 رأس

$$
\text { ماشية يكون كالآتي: }
$$

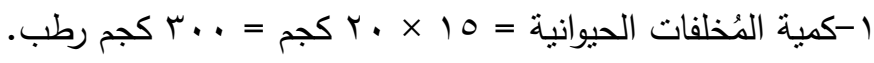

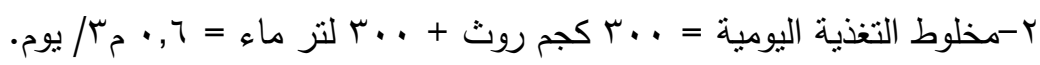

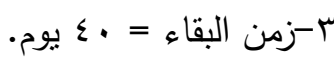

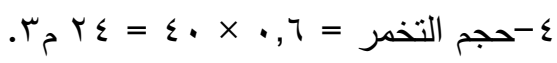


سماد البيوجاز: يُطلق على المخلوط المتبقي من عملية تخمر المخلفات العضوية والخارج من

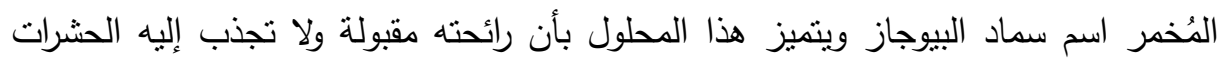

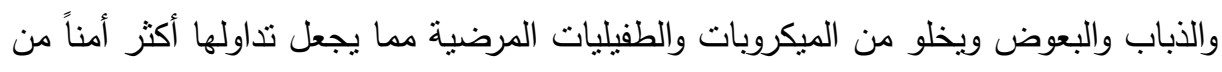
الناحية الصحية عن التعامل مع المخلفات العضوية الأصلية قبل عملية التخمر . وكذللك تتير تحليل سماد البيوجاز إلى احتوائه على بعض الفيتامينات ولاسيما فيتامين

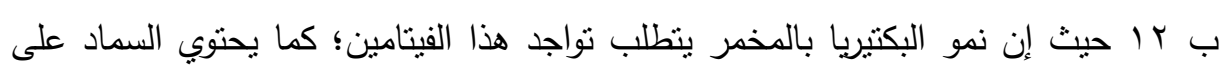
مُنظمات النمو والهرمونات النباتية الطبيعية. ويتكون سماد البيوجاز الناتج بعد إنتاج الغاز من طبقتين الأولى هي سائلة وتحتوي على النى

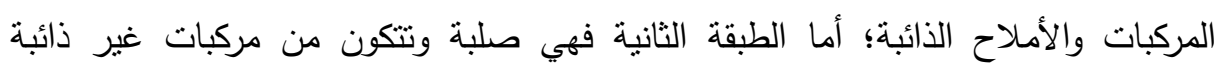

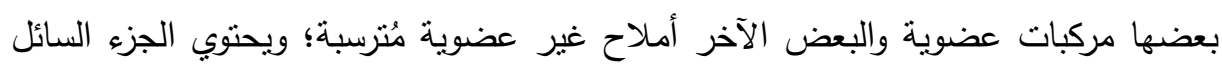

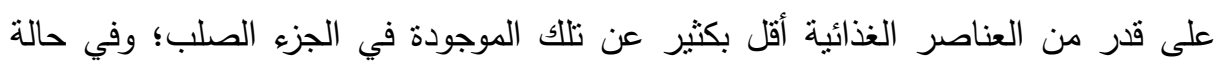

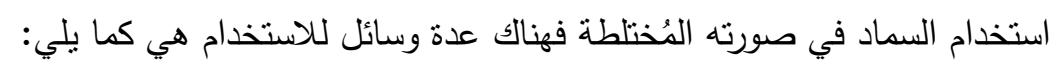
• استخدام مخلوط السماد في صورته السائلة مبانشرة. • التجفيف المباشر تحت الظروف الجوية العادية.

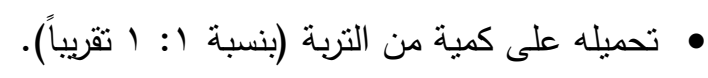

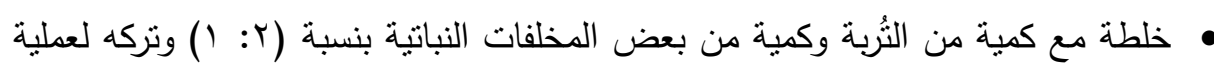
الكمر الهوائي لفترة ولحين الاستخدام.

وقد أوضحت التجارب الحقلية زيادة في إنتاجية المحاصيل المسمدة بسماد البيوجاز عن الإن تلك المُسمدة بالأسمدة البلدية والكيماوية حيث بلغت الزيادة في محصول الذرة الذبادة الثامية

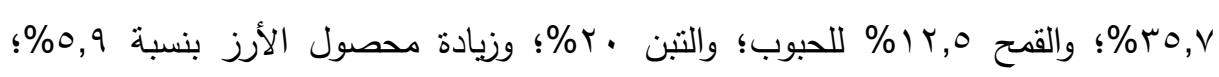

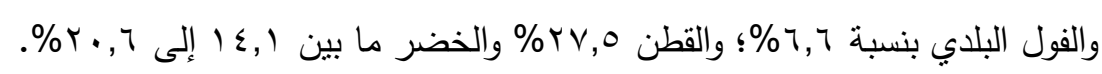
وكان للأثر المتنقي لسماد البيوجاز بعد جني المحصول الأول دوراً في زيادة إنتاجية

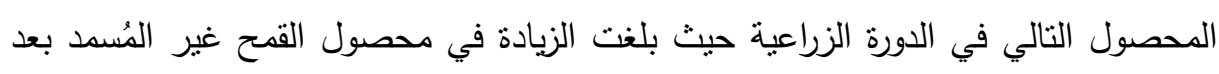
الأرز الذي تم تسميده بسماد البيوجاز ع,11\% وكانت الزيادة للفول البلدي بعد القطن 
معدلات إضافة سماد البيوجاز للمحاصيل المختلفة: ( سعيد عبد العزيز ؛ ب ب ) ): يحتوي

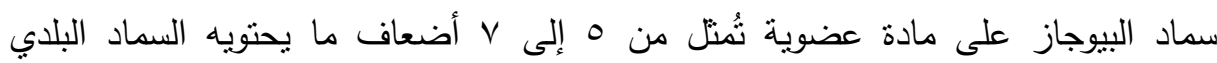
العادي؛ ولذلك يجب الأخذ في الاعتبار هذا التفوق عند استخدام سماد البيوجاز للمحاصيل

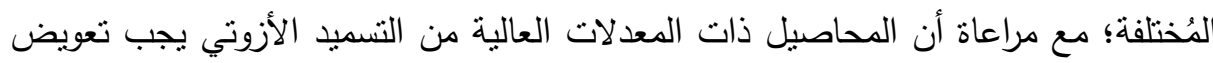
كميات الأزوت التي تحتاجها بإضافة أسمدة معدنية لاستكمال احتياجات النبات.

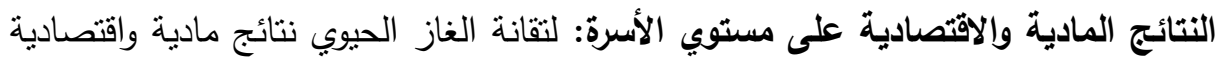
متعددة أهمها: • الكلفة المنخفضة لإنتاج واستثمار الغاز الحيوي بالمقارنة مع أثنكال الطاقة الآخري المستعملة كالكيروسين وغاز البوتان الناتجة عن توفر الغاز دائماً وبجهة أقل.

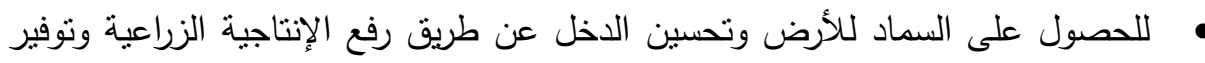
الوقت والجهر والمحافظة على نظافة البيت والقرية. • تغير وتطور في حياة الفلاح الذي يستخدم هذه التقنيات حيث سيقوم بإنشاء الحظائر وبناء المراحيض والحمامات والمطابخ. النتائج الاجتماعية والصحية: • نوفر هذه التقنيات للعائلة وقوداً نظيفاً للاستهلاك المنزلي وتجنبها جهاً شاقاً لجمع ونقل الحطب وبقايا المزروعات لاستخدامها كوقود، مما يوفر لها وقت أكبر لرعاية أطفالها والمساهمة في أعمال إنتاجية أخري نزيد من دخل الأسرة.

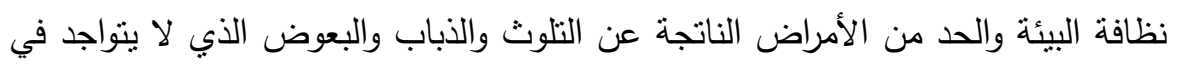
بيئة نظيفة وما ينتج عن ذلك من انخفاض في نسبة الوفيات لا سيما عند الأطفال.

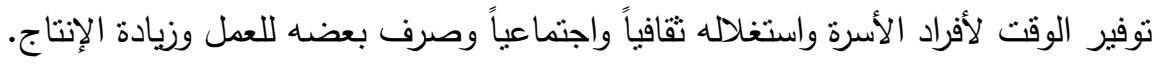

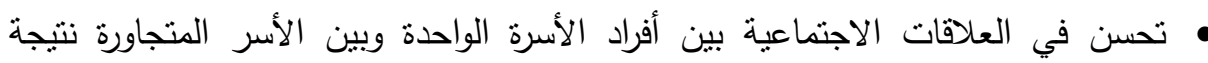
تحسن الوضع الاقتصادي وتوفر الوقت. • نظافة القرية والمنزل وظهور المساحات الخضراء حول المساكن يحقق للسكان رفاهية ويضفي جو من البهجة والسعادة تتشط الإنسان وتدفعة للعمل والإنتاج برغبة ومنعة. 


\section{سبل تعميم استخدام تقنية الغاز الحيوي:}

أولاً: نشر المعرفة: وينم ذلك عن طريق إجراء حملات التوعية على جميع المستويات والقيام بدورات تثقيفية وتدريبية تهدف إلى تصني: • تعريف البعض وتعميق المعرفة لدي الآخر بأبعاد تقنية الغاز الحيوي.

$$
\text { نشر الوعي حول فوائد استخدام هذه التقنية. }
$$

إيضاح المهمات التي تقع على عاتق المستقيدين ومتخذي القرار وممثلي المنظمات الثعبية وتحديد الدور الذي يمكن أن يلعبه كل منهم بهذا الخصوص.

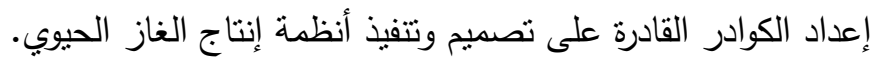

ثانياً: إقامة أطر مؤسساتية تشمل الأجهزة المتكاملة لعمليات التمويل والتصميم والخدمات الفنية وعليها اتخاذ الإجراءات التالية: • القيام بالدراسات الأولية التي تبين إمكانية الإفادة من هذه الثقنية في ريف المنطقة

إنثاء عدد من وحدات إنتاج الغاز الحيوي التوضيحية بغرض التبيان العلمي والميداني وتوضيح التعامل مع هذه التقنية وتبيان مداخلاتها ومخرجاتها ومدي الفائدة منها وتقييم النتائج من النواحي الفنية والاقتصادية والاجتماعية.

• العمل على توعية سكان الريف بالوسائل المناسبة لتشجيع التقبل الاجتماعي لهذه التقنية.

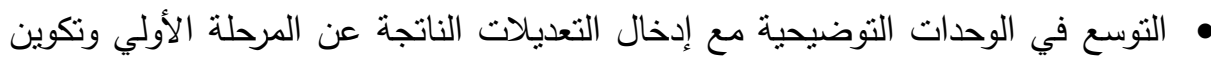

$$
\text { تجارب رائدة في المنطقة. }
$$

• إيجاد نظام الدعم المالي لوحدات إنتاج الحيوي وخاصة نوفير قروض ميسرة المقروبين الراغبين في إنشاء وحدات إنتاج الغاز الحيوي مع حث الجهات المعنية على دعم أسعار

$$
\text { الموارد المستخدمة. }
$$

• الإثراف والمتابعة لوحدات إنتاج الغاز الحيوي التي تم بناؤها بغرض التأكد من استمرارية عملها وكفاءة أدائها، وإعداد برامج تدريبية لتأهيل وتدريب فرق فنية محلية لأغراض • وضع خطة عمل لنشر استخدام التقنيات الملائمة لوحدات إنتاج الغاز الحيوي.

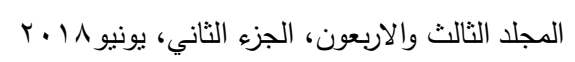


الأبعاد الاقتصادية والبيئية لإنشاء وحدات البيوجاز : يتتاول هذا الجزء وصفا لطريقة قياس كل من المتغيرات المستقلة التي تؤثر علي البعد البيئي والاقتصادي لوحدا البيوجاز كما يتتاول أيضا المتغيرات التابعة والتي تتمثل البعد الاقتصادي والبيئي.

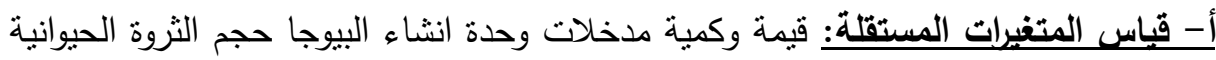
- مخرجات وحدة انتاج البيوجاز - حجم الحيازة الزراعي - الاسئلة الخاصة بالوحدة

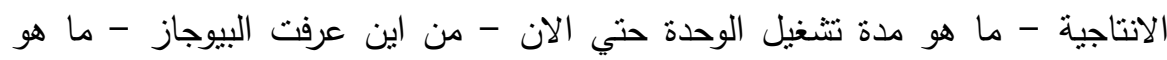

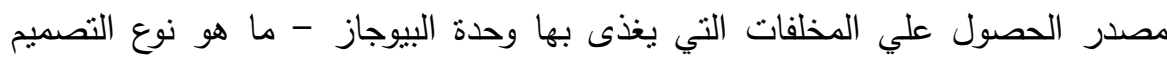
المستخدم في وحدة البيوجاز • ماسل ب- قباس المتغير التابع:تم قياس اثرمشروع البيوجاز علي مستوي المحلي بمقياسين وهم البعد الاقتصادي والبعد البيئي والصحي.

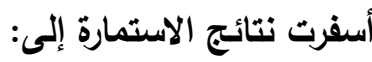

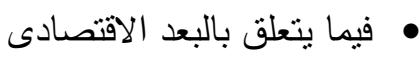

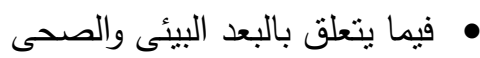

أولاً: البعد الاقتصادي لانشاء وحدات البيوجاز : والذي تم قياسه بتوجيه عددة اسئلة للمستقيدين

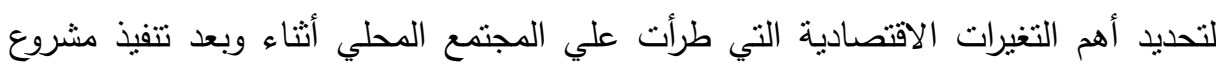
البيوجاز وذللك من خلال تحديد أهم الاسئلة التي تؤثر علي البعد الاقتصادي والتي تتمثل فيما لتئي

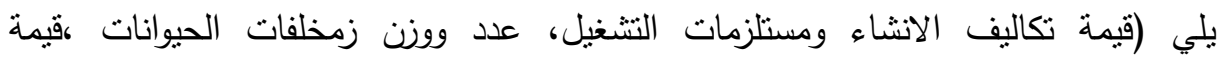
مخرجات وحدة البيوجاز، وحجم الحيازة، منوسط كمية المخلفات المتوفرة والمغذية للوحدة، مساحة الوحدة، سعر بيع وشراء الروث، مدة نتغيل الوحدة، مصادر شراء الوحدة، كيفية

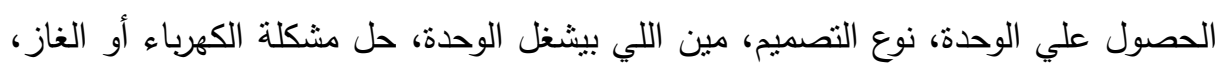

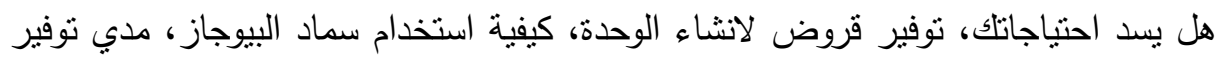

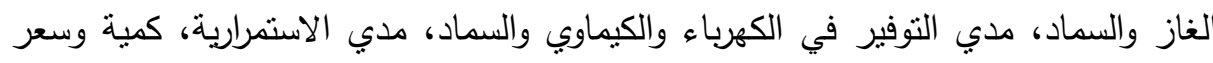
الغاز الناتج، تكلفة العمالة، مدي وجود الاعطال من عدمة، مدة الصيانة، ما هي التكلفة التي يتحملها صاحب الوحدة والمشروع، هل اقامة الوحدة تابعة للمشروع ). 
ثنانياً: البعد البيئي والصحي لإنشاء وحدات البيوجاز : والذي تم قياسه بتوجيه عددة اسئلة للمستفيدين لتحديد أهم التغيرات البيئية والصحية التي طرأت علي المجتمع المحلي أثناء وبعد تتفيذ مشروع البيوجاز وذلك من خلال تحديد أهم الاسئلة التي تؤثر على البعد الصحى والبيئى لئى

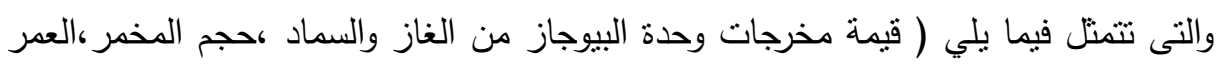

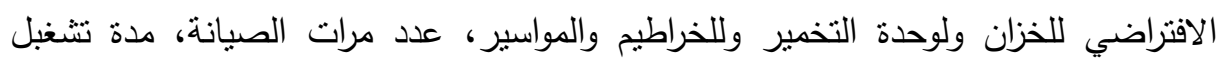
الوحدة، عرفت من أين البيوجاز، مصادر الحصول علي المخلفات، هل ينم تسليم الناتج لثركات متخصصة لبيعها، كيفية التصرف في المخلفات، هل زرت وحدات فبل ذللك، كيفية استخدام الناتج من الوحدة، هل يوجد مصدر أمان، هل راضي عن الوحدة، هل يوجد مخاطرة

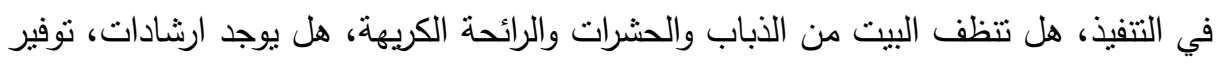
قروض لانثاء الوحدة،هل الوزارة نوضح كيفية الاستفادة من المخلفات في النتابه

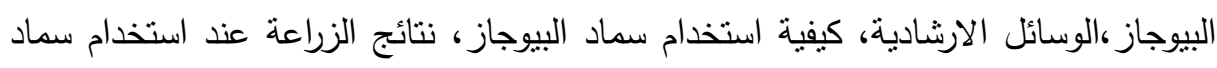

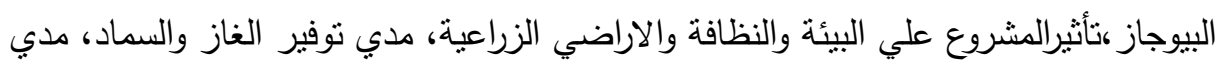

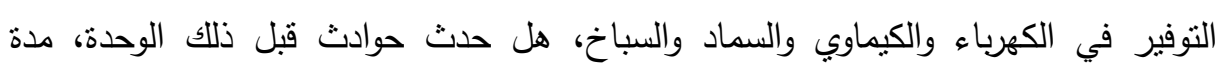
الصيانة، هل اقامة الوحدة تابعة للمشروع).

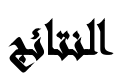

المتغيرات المستقلة المرتبطة بالبعد الاقتصادي: تم عمل العديد من المحاولات

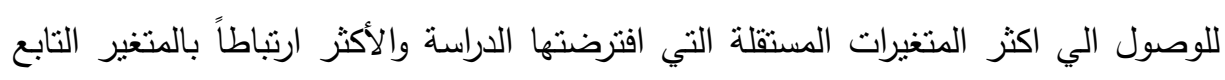

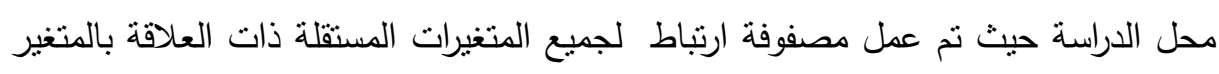

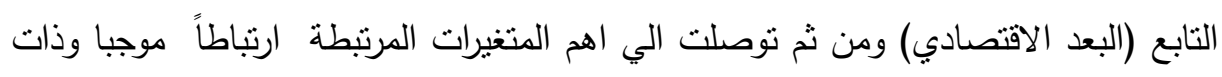

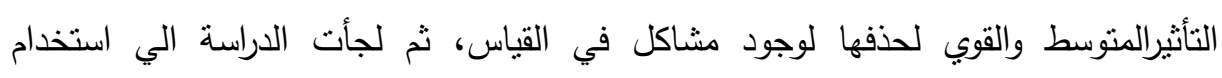

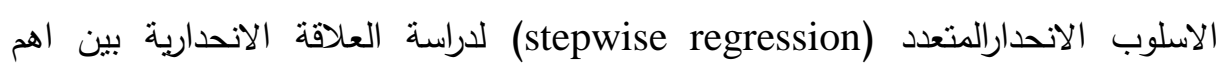

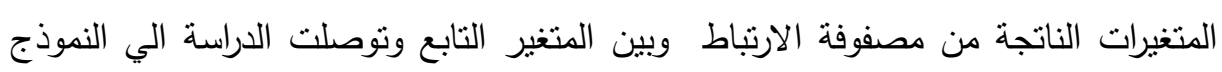
الآتي:

$$
\begin{array}{r}
\ln y_{1}=\propto+\ln x_{7}+\ln x_{9}+ \\
+\ln x_{42}+l
\end{array}
$$




\begin{tabular}{|c|c|c|}
\hline البعد الاقتصادي. & $=$ & $\ln Y_{1}$ \\
\hline سعر العمالة البشرية بالجنية . & $=$ & $\ln X_{7}$ \\
\hline عدد الابقار • ع & $=$ & $\ln X_{9}$ \\
\hline وزن الابقار بالكجم. & $=$ & $\ln X_{10}$ \\
\hline حجم المخلفات الكلية للابقار لتز / يوم. & $=$ & $\ln X_{11}$ \\
\hline حجم المخلفات الكلية للجاموس لتز / يوم. & $=$ & $\ln X_{1}$ \\
\hline قيمة سماد البيوجاز بالجنية . & $=$ & $\ln X_{r r}$ \\
\hline تفتكر بتوفر قد اية في الثهر بعد انشاء الوحدة. & $=$ & $\ln X_{\varepsilon}$. \\
\hline ما مدي تكلفة استخدام الانبوبة بعد تتفيذ الوحدة . & $=$ & $\ln X_{\varepsilon r}$ \\
\hline مدي التوفير في الكيماوي اللى بنستخدمة بعد انشاء الوحدة . & $=$ & $\ln X_{\varepsilon 0}$ \\
\hline ما هي المدة التي تحتاجها الوحدة للصبانه . & $=$ & $\ln X_{o r}$ \\
\hline هل اقامة الَّحدة تابعة للمشروع · & $=$ & $\ln X_{0 \varepsilon}$ \\
\hline
\end{tabular}

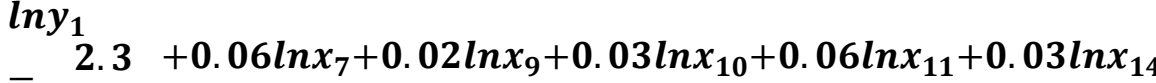

$$
\begin{aligned}
& =(10.9) \quad(3.8) \quad(2.5) \quad(10.9) \quad \text { (4.1) }
\end{aligned}
$$

$0.03 \ln x_{22}+0.05 \ln x_{40}+0.04 \ln x_{42}+0.07 \ln x_{45}+0.3 \ln x_{52}+0.4 \ln x_{54}$
(3.2)
(3.8)
(4.4)
(9.1)
(10.8)
(23.1)

\begin{tabular}{|c|c|c|}
\hline $\mathbf{F}$ & R Square & R Square Adjusted \\
\hline \hline $9 \vee \varepsilon, \wedge$ & $\cdot, 990$ & $\cdot, 99 \varepsilon$ \\
\hline
\end{tabular}

وبدراسة العلاقة الانحدارية والارتباطية بين المتغيرات محل الدراسة باعتبار ان البعد

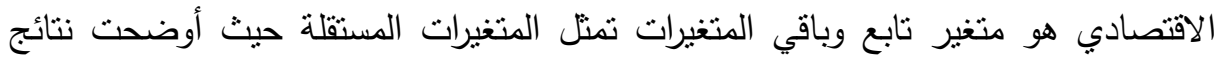
التقدير الاحصائي ان اهم المتغيرات التي تؤثز علي البعد الاقتصادي (سعر العمالة البشرية

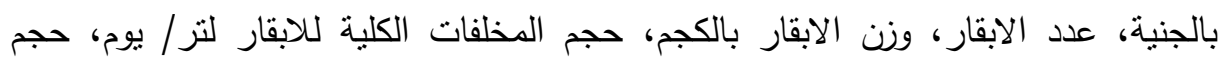

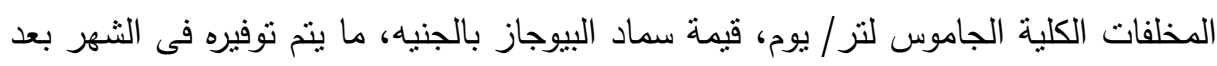

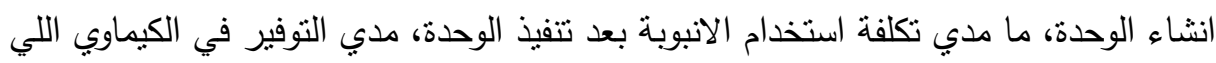

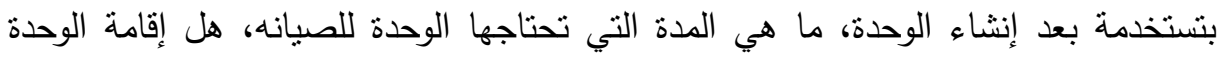

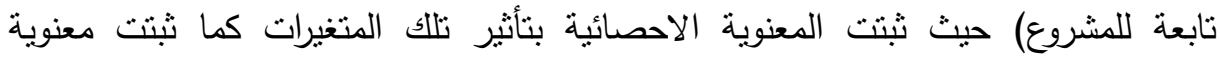

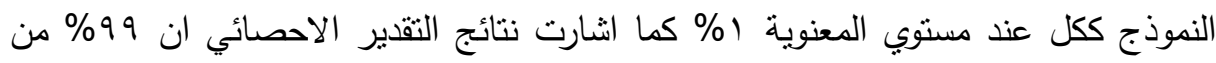


التغيرات الحادثة في البعد الاقتصادي ترجع الي تلك المتغيرات المستقلة محل الدراسة وهناك ا من التغيرات التي لم تأخذ في الاعتبار .

ولتحديد نسبة مساهمة كل من هذه المتغيرات في تقسير جزء من التباين في البعد

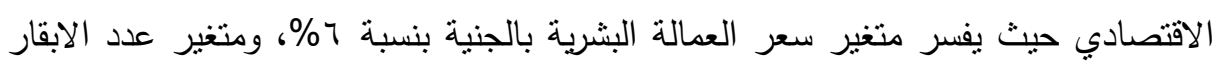

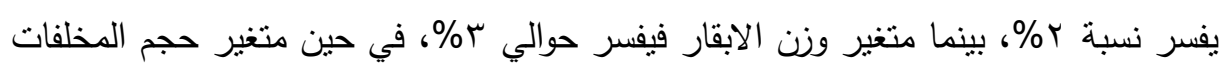

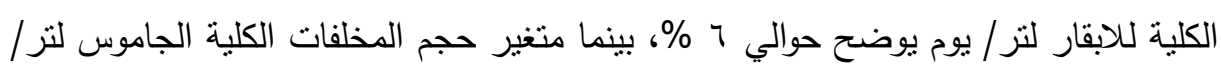

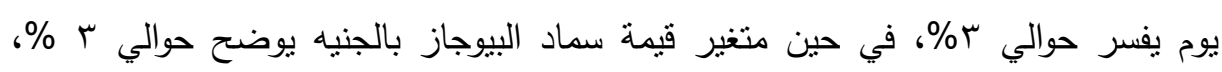

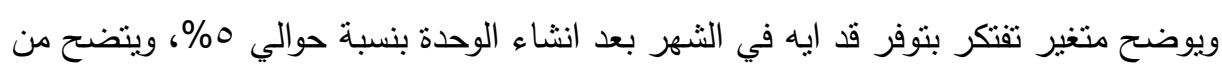

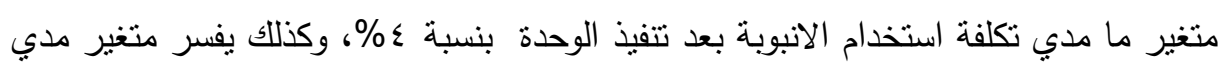

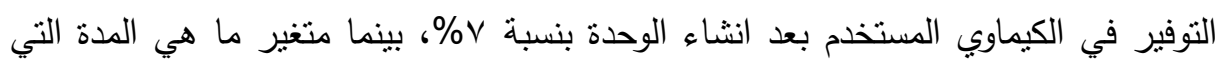

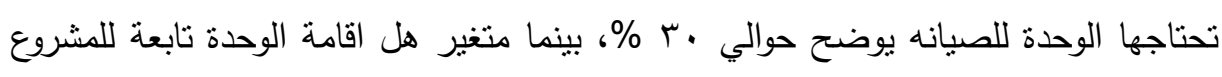

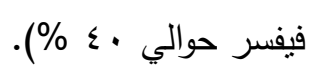
المتغيلات المستقلة المرتطة بالبعد البيئي والصحي: تم عمل العديد من المحاولات للوصول

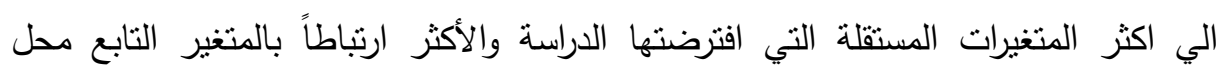

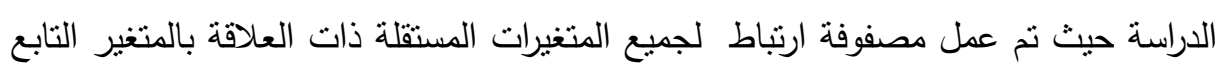

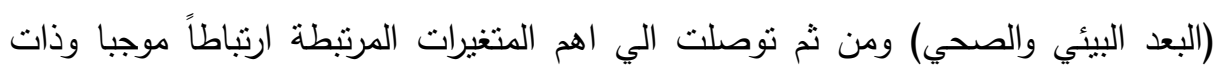

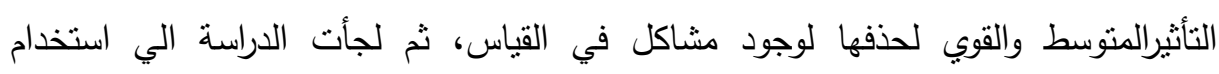

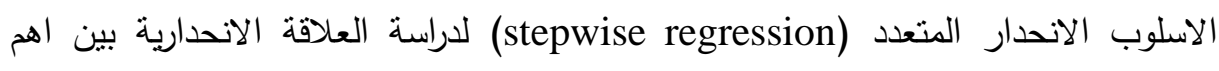

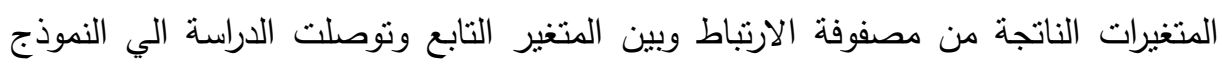
الآتي:

$$
\ln y_{1}=\propto+\ln x_{2}+\ln x_{3}+\ln x_{33}+\ln x_{11}+\ln x_{14}+\ln x_{33}
$$

\begin{tabular}{|c|c|c|}
\hline البعد البيأي والصحى. & $=$ & $\ln Y_{1}$ \\
\hline قيمة سماد البيوجاز بالجنية & $=$ & $\overline{l n} X_{r}$ \\
\hline حجم المخمر الخاص بوحدتلك & $=$ & $\ln X_{r}$ \\
\hline هل زرت وحدة أو أكثر للبيوجاز قبل ما يكون عندك وحدة . & $=$ & $\ln X_{1 \varepsilon}$ \\
\hline ما مدي التوفير في الكيماوي في السنة & $=$ & $\ln X_{r r}$ \\
\hline
\end{tabular}

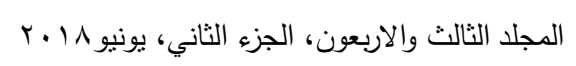




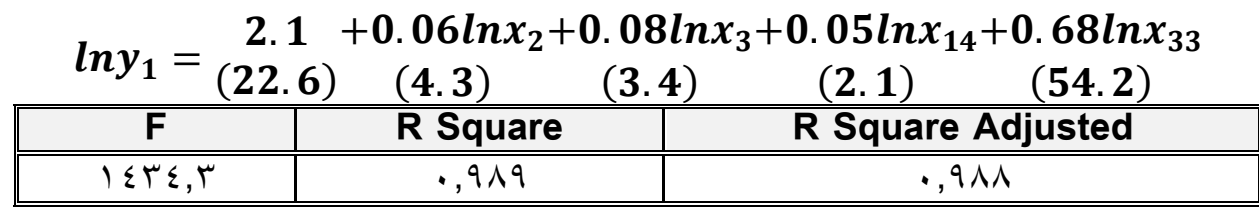

ولتحديد نسبة مساهمة كل من هذه المتغيرات في تفسير جزء من التباين في البعد البيئي

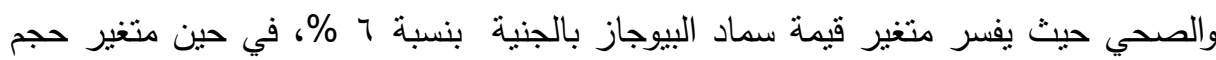
المخمر الخاص بوحدتك يفسر نسبة حوالي ^^\%، وبالنسبة لمتغير هل زرت بهنه وحدة أو أكثر للبيوجاز قبل ما يكون عندك وحدة بنسبة ٪\%، في حين يفسر متغير ما مدي التوفير في

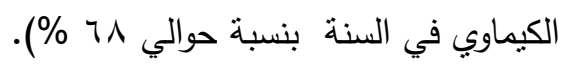
البعد البيئي لإنتاج البيوجاز : تهدف تكنولوجيا البيوجاز الي التخمر اللاهوائي للمواد العضوية الصلبة والسائلة منل روث الماشية والدواجن والاغنام، والاحطاب والقش لانتاج غاز الميثان

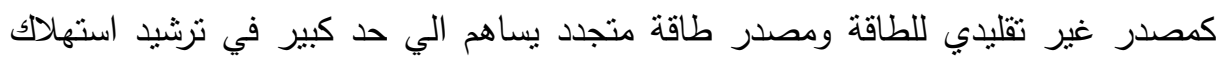
الطاقة النقليدية الناضبة والتي زادت المعدلات الحالية لاستخدامها في القري منل البوتاجاز والكيروسين وكذلك حماية للمنتجات الزراعية الثانوية مثل مخلفات المحاصيل الحقلية وروث

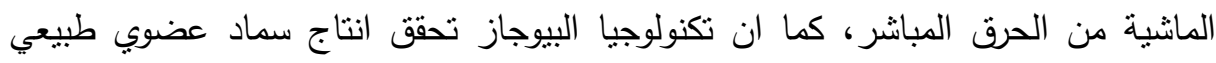
يتميز بارتفاع محتواه من المادة العضوية والعناصر السمادية واحتوائه علي الفيتامينات والهرمونات الطبيعية، وبالتالي فان تكنولوجيا البيوجاز تساهم في خفض تكلفة الانتاج الزراعي

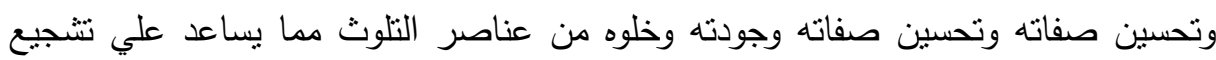
تصديره لمطابقاته للمواصفات العالمية المطلوبة وكذللك توفير فرص عمل جديدة بالريف ورفع المستوي البيئي والاجتماعي والصحى للمرأة الريفية.

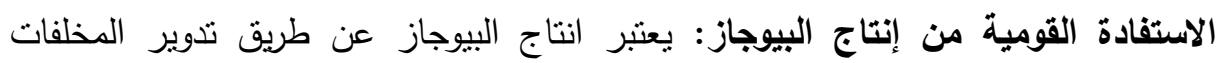

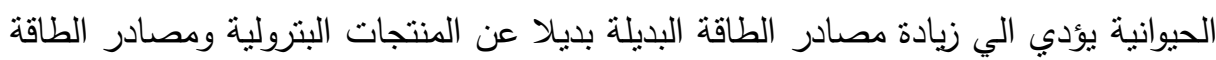

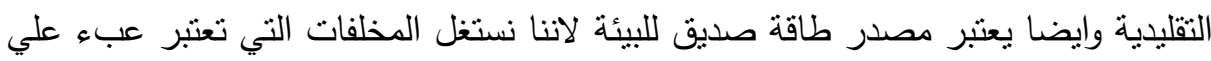
المزارع لكيفية التخلص الامن لها وتعتبر عبء علي الدولة لايجاد طرق التخلص السليمة 
لتساعد المزارع لانتاج الطاقة ،وايضا الطاقة الناتجة طاقة نظيفة وايضا نوفير العملة الصعبة المستغلة لاستيراد الطاقة من الخارج.

\section{الميوكيات}

• استخلال المخلفات الحيوانية بتحويلها إلى طاقة يجعل لها قيمة اقتصادية ومصدر متجدد للطاقة كلما يزيد حجمه نزيد الطاقة المنتجة منه • تدوير المخلفات الحيوانية وإعادتها إلى سلعة لها قيمة اقتصادية يساهم فى تحقيق عائد

$$
\text { للمنتج فى الريف المصرى }
$$

• طرح وحدات البيوجاز بمختلف السعات على حسب مقدار الحاجة والمخلفات بداية النهايه

$$
\text { للاعتماد الكلى على البيوجاز }
$$

ه البيوجاز غاز نظيف والناتج من وحدات البيوجاز من سماد يعد الأفضل كسماد للمحاصيل

$$
\text { الزراعية لزيادة الإنتاج. }
$$

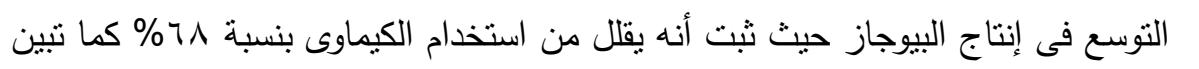
من النتائج.

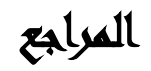

تقرير الدراسات العمدة الإنمائي (UNDP) IPCC2001

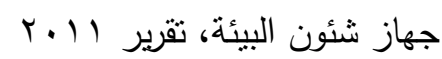

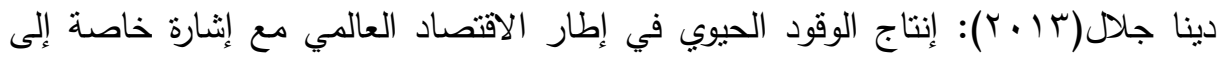

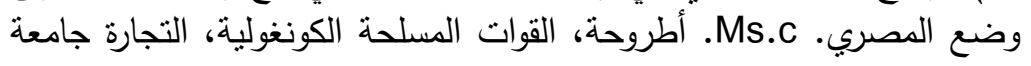

$$
\text { بورسعيد }
$$

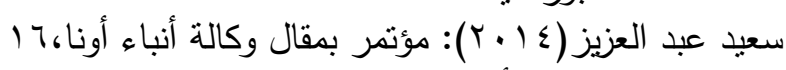

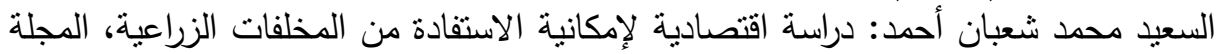

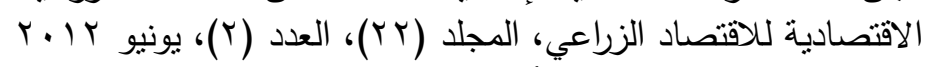

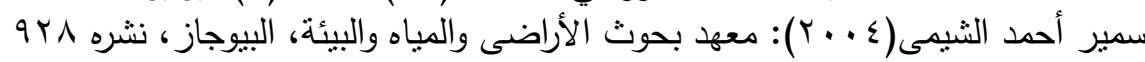

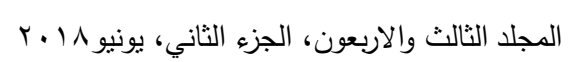




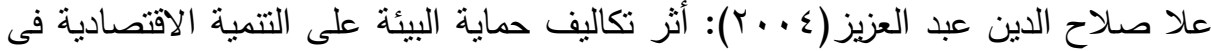

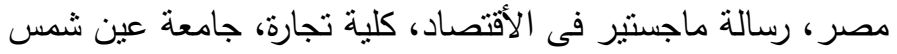

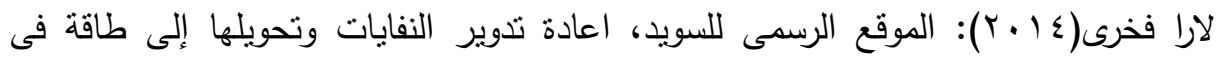
السويد

محمد إبراهيم(· (ب): الدراسة الأولية لتسويق مشروع الغاز الحيوي لتحقيق التتمية الريفية

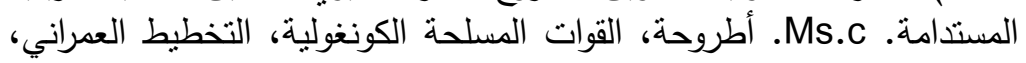

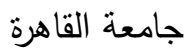

مسعد السعيد رجب، خيري حامد العشماوي، سمير محمود رضوان، أحمد عبد ربه عاديه عامر:

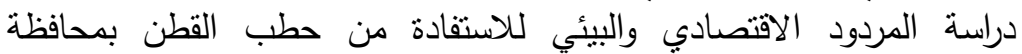

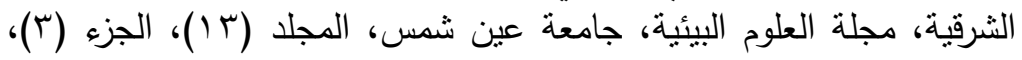
Y.. T

"PISCES" المنظمة والوزارة البريطانية للتتمية الدولية خلال الفترة سبتمبر ، نوفمبر

Dina, G. (2013): The production of biofuels in the framework of the global economy with particular reference to the situation of the Egyptian. Ms.c. thesis. Fac. of Commerce Port Said University.

Ebrehem, R. and Mohamed R. (2010): The initial study for the marketing of bio- gas project to achieve sustainable rural development. Ms.c. thesis. Fac. of Urban Planning, Cairo university .

Elshemy, S.A. (2004): Biogas. Water and soil Environment Research Institute - Agriculture Research Center. (928).

Organization and the British Ministry for International Development During the period September, November "PISCES".

Scientific studies report issued by the Intergovernmental Panel on Climate Change IPCC2001.

The United Nations Development Programme ( UNDP ).

Environmental Affairs Agency, 2011 Report

Said Abdulaziz (2014): A conference with Ona news agency article, 16.

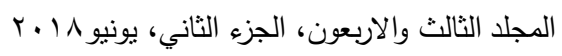


Ola Salah Al-Din Abdulaziz (2004): Effect of Environmental Protection Costs on Economic Development in Egypt, Master Thesis in Economics, Faculty of Commerce, Ain Shams University.

Lara Fakhry (2014): Sweden's official site, waste recycling and energy conversion in Sweden

The study of economic and environmental benefits to benefit from cottonwood in Sharqia Governorate, Journal of Environmental Sciences, Ain Shams University, vol. 13, part 3, 2006.

Saudi Mohammad Shaban Ahmed: Economic Study On The Possibility of Use of Agricultural Waste, Economic Economic Economy Magazine, Vol. 22, No. 2, June 2012.

\title{
ENVIRONMENTAL AND ECONOMIC ASSESSMENT \\ OF BIOGASS PRODUCTION IN THE EGYPTIAN \\ COUNTRY SIDE
}

Mahmoud, M. S. ${ }^{(1)}$; El Kassas, H. I. ${ }^{(2)}$; Abdelrazek, T. A. M. ${ }^{(2)}$ and Abdelhamed, Seham, A. ${ }^{(2)}$

1) Ministry of Environmental Affairs 2) Institute of Environmental Studies and Research, Ain Shams University

\begin{abstract}
The research problem is that Egypt is facing the problem of accumulation of garbage and animal waste, crises of unavailability of potane pipes and the burning of rice straw. Therefore, the research aims at exploiting the energy of biogas and other clean and new energies. If we are to solve the scientific problem of energy, May help to solve this problem, and some research can be applied on the ground in weeks, and the technologies that need to be implemented only a few weeks, the
\end{abstract}

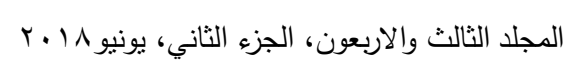


project biogas or biogas, and biogas is the gas due to the decomposition of oxygen organic matter. Biogas is derived from organic matter, a type of biofuel. The study aimed at conducting an economic assessment of the ways in which farmers use animal waste The biogas project ensures a safe way to get rid of some animal waste, produces cheap gas, and can be used to generate electricity in some rural homes. Bioenergy technology is beneficial to the national economy in terms of optimal use of animal waste in the countryside. According to the latest statistics issued by the Ministry of Agriculture, About 8 million heads of livestock produce 93 million kilograms of organic waste a day, and try to take advantage of these wastes and convert them into bioactive gas that will produce about 4 million cubic meters of bio-gas per day. This amount is enough to produce 43 million (12.5\% of Egypt's total gas consumption per year). Bioenergy is expected to become an economic driving force in the near future in the Egyptian countryside as a source of thermal energy. Biogas can compress, Is largely used for the supply of mechanical vehicles with energy. Biogas is a renewable fuel that qualifies for renewable energy support, organic fertilizer for soil fertilization, feed production for animal feed and other applications, and may help to eliminate the accumulation of animal and animal waste. Plant The energy crisis and the increase in prices in Egypt required the study and treatment of new alternative methods to obtain clean energy. Therefore, the aim of the research was the disposal of animal waste in a proper way by converting it into energy through biogas units. The research relied on the descriptive approach to data collection and obtaining results through research and books Scientific and periodic reports and articles. The results of the research showed that the use of biogas units achieves very high economic and environmental efficiency and contributes to the disposal of the problem of animal waste. There is no doubt that the problem of the spread of diseases due to the abundance of animal waste To try to reach a final solution to this crisis and therefore we found that the exploitation of this wealth of animal waste to obtain clean energy.

The field study was conducted for a sample of governorates for 71 units:

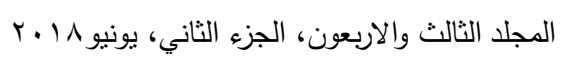


1- Governorate of Eastern and 19 units 2 - Fayoum Governorate and the number of 18 units 3 - Governorate of Minya and the number of 28 units and the number 4 - Assiut and the number of 3 units 5 Menoufia and 2 units 6 - Al - Luxor 1 units

\section{The most important results were:}

1. The most important economic factors affecting the production of biogas were found in the study sample: Price of labor, number of cows, weight of cows, volume of waste, value of biogas fertilizer, savings per month after establishment of the unit, cost of using the tube after implementation of the unit, extent of chemical savings after establishment of the unit.

Affecting 6\%, 2\%, 3\%, 6\%, 3\%, 3\%, 5\%, 4\%, 7\%, 3\% and 4\%, respectively.

2. The most important factors related to the environmental and health dimension are also shown in the study sample: The value of the biogas fertilizer, the unit size of your unit, did you visit the Biogas unit before establishing your unit, the chemical savings in the year.

Affecting 6\%,8\%, 5\% and 68\%, respectively.

Therefore, the study recommends: the expansion of biogas production, which proved to reduce chemical use by $68 \%$ as shown by the results.

Keywords: biogas, economic assessment, environmental assessment

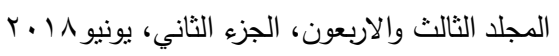

